\title{
A Cascaded Multilevel Inverter Based DSTATCOM for Restructured Power Systems to Compensate the Reactive Power and Harmonics Using Shift Carrier Techniques
}

\author{
D. Mohan Reddy ${ }^{1}$, Dr.T.Gowrimanohar ${ }^{2}$ \\ ${ }^{I}$ Associate professor, Department of EEE, SVIET, Machilipatnam ; Krishna (Dt); A.P, India. \\ ${ }^{2}$ Associate professor, Department of EEE, SV University, Tirupati; Chittoor (Dt); A.P, India
}

\begin{abstract}
The "multilevel converter" has drawn tremendous interest in the power industry. The general structure of the multilevel converter is to synthesize a sinusoidal voltage from several levels of voltages, Multilevel voltage source converters are emerging as a new breed of power converter options for high power applications, These converter topologies can generate high-quality voltage waveforms with power semiconductor switches operating at a frequency near the fundamental. Among the available multilevel converter topologies, the cascaded multilevel converter constitutes a promising alternative, providing a modular design that can be extended to allow a transformer less connection. This paper presents a three-phase, seven level cascaded multilevel voltage source inverter based DSTATCOM for power line conditioning to improve power quality in the distribution network. Finally a level shifted PWM (LSPWM) and phase shifted PWM (PSPWM) techniques are adopted to investigate the performance of CHB Inverter based DSTATCOM. The results are obtained through Mat lab / Simulink software package.
\end{abstract}

Keywords- DSTATCOM, Instantaneous power theory, Power quality, Triangular-sampling current modulator, Cascaded H- Bridge Multilevel Inverter.

\section{Introduction}

In recent years Electrical Power Quality had obtained more attention in power engineering. In present day's power distribution systems is suffering from severe power quality problems. These power quality problems include high reactive power burden, harmonics currents, load unbalance, excessive neutral current etc. The measure of power quality depends upon the needs of the equipment that is being supplied. What is good power quality for an electric motor may not be good enough for a personal computer. Usually the term power quality refers to maintaining a sinusoidal waveform of bus voltages at rated voltage and frequency [1]. The waveform of electric power at generation stage is purely sinusoidal and free from any distortion. Many of the Power conversion and consumption equipment are also designed to function under pure sinusoidal voltage waveforms. However, there are many devices that distort the waveform. These distortions may propagate all over the electrical network. In recent years, there has been an increased use of non-linear loads which has resulted in an increased fraction of non-sinusoidal currents and voltages in Electric Network. The wave shape phenomena associated with power quality may be characterized into synchronous and non synchronous phenomena. Synchronous phenomena refer to those in synchronism with A.C waveform at power frequency [2],[3].

A group of controllers together called Custom Power Devices (CPD), which include the DSTATCOM (distribution static compensator), The DSTATCOM, is a shunt-connected device, which takes care of the power quality problems in the currents It consists of a dc capacitor, three-phase inverter (IGBT, thyristor) module, ac filter, coupling transformer and a control strategy. The basic electronic block of the D-STATCOM is the voltage-sourced inverter that converts an input dc voltage into a three-phase output voltage at fundamental frequency. The D-STACOM employs an inverter to convert the DC link voltage $\mathrm{V}_{\mathrm{dc}}$ on the capacitor to a voltage source of adjustable magnitude and phase. Therefore the D-STATCOM can be treated as a voltagecontrolled source. The D-STATCOM can also be seen as a current-controlled source. The generalized instantaneous reactive power theory which is valid for sinusoidal or non-sinusoidal and balanced or unbalanced three-phase power systems with or without zero-sequence currents were later proposed [8]. The construction controller of the D-STATCOM is used to operate the inverter in such a way that the phase angle between the inverter voltage and the line voltage is dynamically adjusted so that the D-STATCOM generates or absorbs the desired VAR at the point of connection. The phase of the output voltage of the thyristor-based inverter, $\mathrm{V}_{\mathrm{i}}$, is controlled in the same way as the distribution system voltage, $\mathrm{V}_{\mathrm{s}}$.

The DSTATCOM is based on the instantaneous real-power theory; it provides good compensation characteristics in steady state as well as transient states [11]. The instantaneous real-power theory generates the reference currents required to compensate the distorted line current harmonics and reactive power. It also tries to 
maintain the dc-bus voltage across the capacitor constant. Another important characteristic of this real-power theory is the simplicity of the calculations, which involves only algebraic calculation [12].

A multilevel inverter can reduce the device voltage and the output harmonics by increasing the number of output voltage levels. There are several types of multilevel inverters: cascaded $\mathrm{H}$-bridge (CHB), neutral point clamped, flying capacitor [2-5]. In particular, among these topologies, CHB inverters are being widely used because of their modularity and simplicity. Various modulation methods can be applied to CHB inverters. CHB inverters can also increase the number of output voltage levels easily by increasing the number of H-bridges. This paper presents a DSTATCOM with a proportional integral controller based CHB multilevel (five level and seven level) inverter for the harmonics and reactive power mitigation of the nonlinear loads. This type of arrangements have been widely used for PQ applications due to increase in the number of voltage levels, low switching losses, low electromagnetic compatibility for hybrid filters and higher order harmonic elimination.

\section{Proposed System}

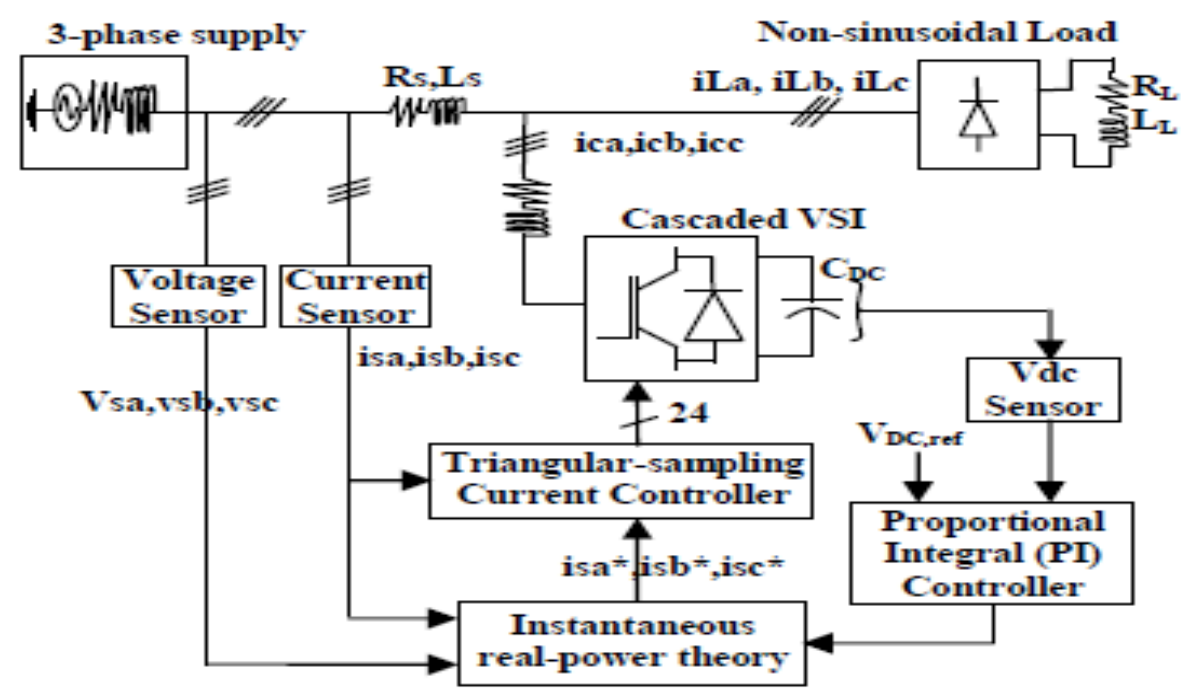

Figure 1: Schematic Diagram of DSTATCOM

Instantaneous real-power theory based cascaded multilevel inverter based DSTATCOM is connected in the distribution network at the PCC through filter inductances and operates in a closed loop. The DSTATCOM system contains a cascaded inverter, RL-filters, a compensation controller (instantaneous real-power theory) and switching signal generator (proposed triangular-sampling current modulator) as shown in the Figure 1. The three-phase supply source connected with non-linear load and these nonlinear loads currents contains fundamental and harmonic components. If the active power filter provides the total reactive and harmonic power, $i_{s}(t)$ will be in phase with the utility voltage and would be sinusoidal. At this time, the active filter must provide the compensation current therefore, active power filter estimates the fundamental components and compensating the harmonic current and reactive power.

\section{A Seven level CHB Inverter}

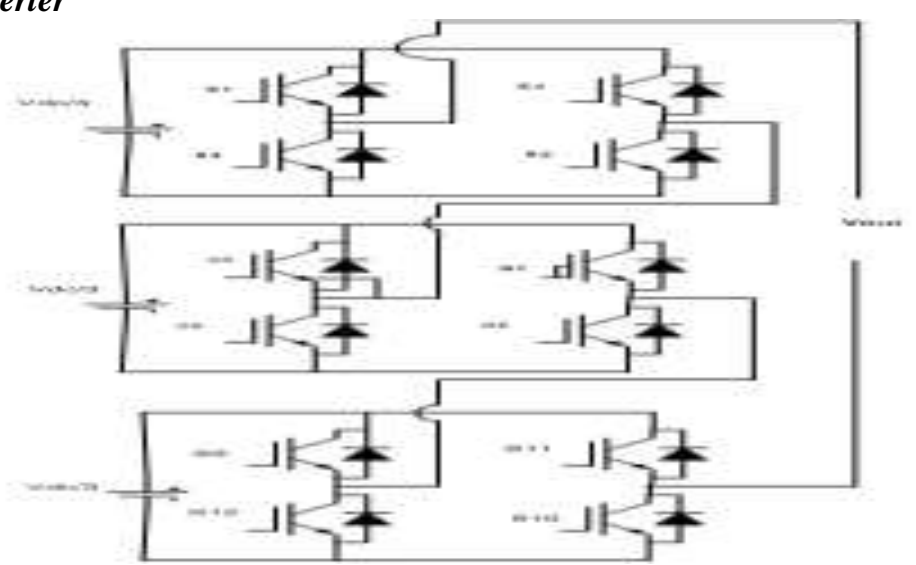

Figure. 2 Seven level CHB inverter 
Figure 2 Shows the seven level multilevel inverter and Table shows the switching states of the seven level inverter

Table I Switching table for Full H-Bridge of seven level inverter

\begin{tabular}{|c|c|}
\hline Switches Turn ON & Voltage Level \\
\hline S1,S2,S6,S8,S10,S12 & Vdc/3 \\
\hline S1,S2,S5,S6,S10,S12 & $2 \mathrm{Vdc} / 3$ \\
\hline S1,S2,S5,S6,S9,S10 & Vdc \\
\hline S2,S4,S6,S8,S10,S12 & 0 \\
\hline S3,S4,S6,S8 S10,S12 & $-\mathrm{Vdc} / 3$ \\
\hline S3,S4,S7,S8,S10,S12 & $-2 \mathrm{Vdc} / 3$ \\
\hline S3,S4,S7,S8,S11,S12 & $-\mathrm{Vdc}$ \\
\hline
\end{tabular}

III. Reference Current control strategy:

The control scheme of the shunt active power filter must calculate the current reference signals from each phase of the inverter using instantaneous real-power compensator. The block diagram as shown in Figure.3, that control scheme generates the reference current required to compensate the load current harmonics and reactive power. The PI controller is tried to maintain the dc-bus voltage across the capacitor constant of the cascaded inverter. This instantaneous real- power compensator with PI-controller is used to extracts reference value of current to be compensated.

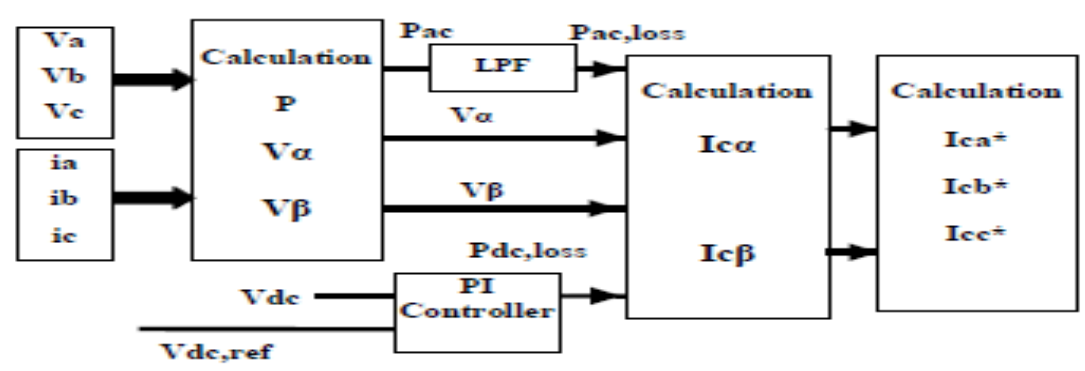

Figure 3: Reference current generator using instantaneous real-power theory

These reference currents $i_{\mathrm{sa}} *, i_{\mathrm{sb}} *$ and $i_{\mathrm{sc}} *$ are calculated instantaneously without any time delay by using the instantaneous $\alpha, \beta$ coordinate currents. The required references current derivate from the inverse Clarke transformation and it can be written as

$$
\left[\begin{array}{l}
i_{g a} * \\
i_{g b} * \\
i_{g c} *
\end{array}\right]=\sqrt{2 / 3}\left[\begin{array}{cc}
1 & 0 \\
-1 / 2 & \sqrt{3 / 2} \\
-1 / 2 & -\sqrt{3 / 2}
\end{array}\right]\left[\begin{array}{l}
i_{c \alpha} \\
i_{c \beta}
\end{array}\right]
$$

The p-q theory performs a Clarke transformation of a stationary system of coordinates a b c to an orthogonal reference system of coordinates $\alpha, \beta$. In a b c coordinates axes are fixed on the same plane, apart from each other by 120 that as shown in Fig 5. The instantaneous space vectors voltage and current $V_{a}, i_{a}$ are set on the aaxis, $\mathrm{V}_{\mathrm{b}}, \mathrm{i}_{\mathrm{b}}$ are on the $\mathrm{b}$ axis, and $\mathrm{V}_{\mathrm{c}}, \mathrm{i}_{\mathrm{c}}$ are on the $\mathrm{c}$ axis. These space vectors are easily transformed into $\alpha, \beta$ coordinates. The instantaneous source voltages $\mathrm{v}_{\mathrm{sa}}, \mathrm{v}_{\mathrm{sb}}, \mathrm{v}_{\mathrm{sc}}$ are transformed into the $\alpha, \beta$ coordinate's voltage by Clarke transformation as follows:

$v_{\alpha \beta 0}=\sqrt{2 / 3}\left[\begin{array}{ccc}1 & -1 / 2 & -1 / 2 \\ 0 & \sqrt{3 / 2} & -\sqrt{3 / 2} \\ 1 / \sqrt{2} & 1 / \sqrt{2} & 1 / \sqrt{2}\end{array}\right] v_{a b c}$

Similarly, the instantaneous source current $i_{\mathrm{sa}}, \mathrm{i}_{\mathrm{sb}}, \mathrm{i}_{\mathrm{sc}}$ also transformed into the $\alpha, \beta$ coordinate's current by Clarke transformation that is given as: 


$$
i_{\alpha \beta 0}=\sqrt{2 / 3}\left[\begin{array}{ccc}
1 & -1 / 2 & -1 / 2 \\
0 & \sqrt{3 / 2} & -\sqrt{3 / 2} \\
1 / \sqrt{2} & 1 / \sqrt{2} & 1 / \sqrt{2}
\end{array}\right] i_{a b c}
$$

Where $\alpha$ and $\beta$ axes are the orthogonal coordinates. They $V_{\alpha}, i_{\alpha}$ are on the $\alpha$-axis, and $V_{\beta}, i_{\beta}$ are on the $\beta$-axis. The reference currents $i_{s a} * i_{s b} *$ and $i_{s c} *$ are compared with actual source current $i_{s a}, i_{s b}$ and $i_{s c}$ that facilitates generating cascaded multilevel inverter switching signals using the proposed triangular-sampling current modulator. The small amount of real-power is adjusted by changing the amplitude of fundamental component of reference currents and the objective of this algorithm is to compensate all undesirable components. When the power system voltages are balanced and sinusoidal, it leads to constant power at the dc bus capacitor and balanced sinusoidal currents at AC mains simultaneously.

\section{PWM Techniques for CHB Inverter}

The most popular PWM techniques used for CHB inverter are

1. Phase Shifted Carrier PWM (PSCPWM)

2. Level Shifted Carrier PWM (LSCPWM)

Case-1:- Phase Shifted Carrier PWM (PSCPWM)

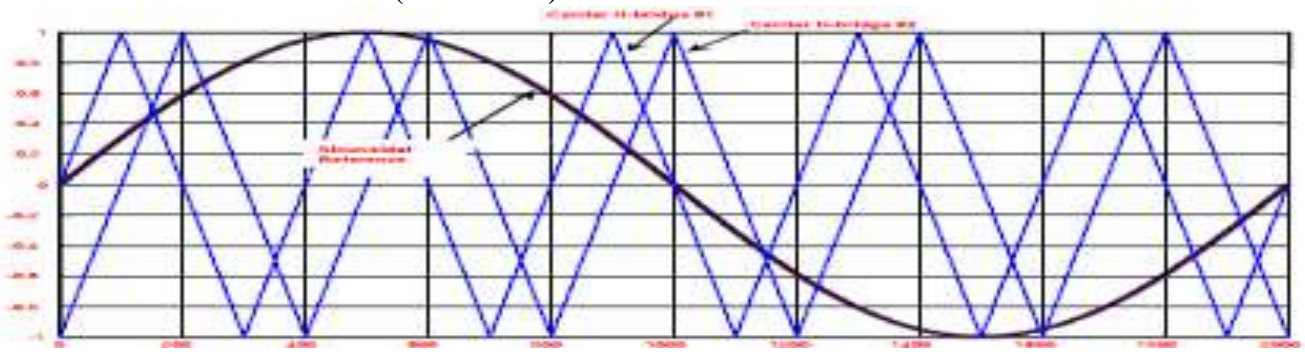

Figure-4 phase shifted carrier PWM

Figure-4 shows the PSCPWM. In general, a multilevel inverter with $m$ voltage levels requires $(m-1)$ triangular carriers. In the PSCPWM, all the triangular carriers have the same frequency and the same peak-topeak amplitude, but there is a phase shift between any two adjacent carrier waves, given by $\varphi_{\mathrm{cr}}=360^{\circ} /(\mathrm{m}-1)$. The modulating signal is usually a three-phase sinusoidal wave with adjustable amplitude and frequency. The gate signals are generated by comparing the modulating wave with the carrier waves. It means for five-level inverter, four triangular carriers are needed with a $90^{\circ}$ phase displacement between any two adjacent carriers. In this case the phase displacement of $V_{c r 1}=0^{\circ}, V_{c r 2}=90^{\circ}, V_{c r l .}=180^{\circ}$ and $V_{c r 2 .}=270^{\circ}$.

Case-2:- Level Shifted Carrier PWM (LSCPWM)

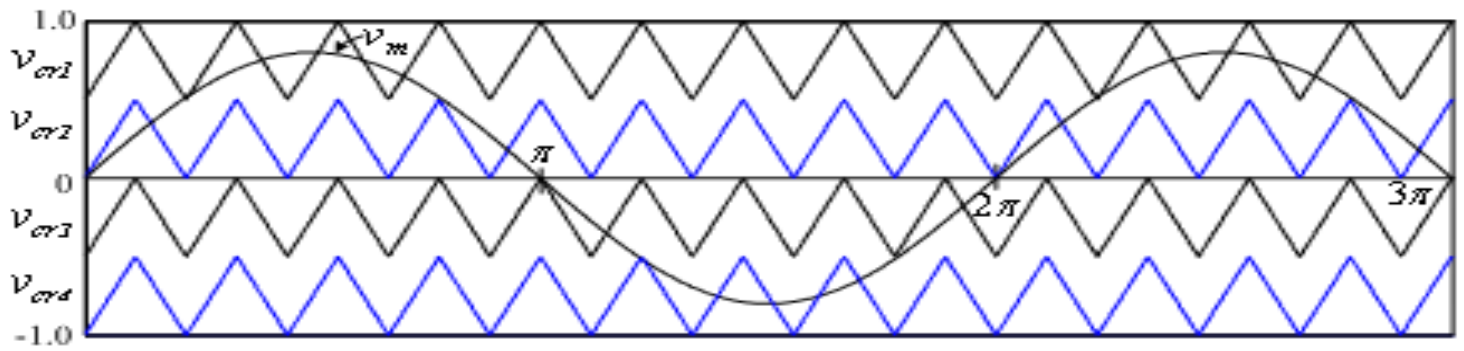

Figure-5 Level shifted carrier PWM (IPD)

Figure-5 shows the LSCPWM. The frequency modulation index is given by

$m_{f}=f_{c r} / f_{m}$,

(4)

where $\mathrm{f}_{\mathrm{m}}$ is modulating frequency and $\mathrm{f}_{\mathrm{cr}}$ are carrier waves frequency.

The amplitude modulation index ' $\mathrm{m}_{\mathrm{a}}$ ' is defined by

$\mathrm{m}_{\mathrm{a}}=\mathrm{V}_{\mathrm{m}} / \mathrm{V}_{\mathrm{cr}}(\mathrm{m}-1) \quad$ for $0 \leq \mathrm{m}_{\mathrm{a}} \leq 1$

Where $V_{m}$ is the peak value of the modulating wave and $V_{c r}$ is the peak value of the each carrier wave [1]. The amplitude modulation index, $\mathrm{m}_{\mathrm{a}}$ is 1 and the frequency modulation index, $\mathrm{m}_{\mathrm{f}}$ is 6 . The triggering circuit is designed based on the three phase sinusoidal modulation waves $\mathrm{V}_{\mathrm{a}}, \mathrm{V}_{\mathrm{b}}$, and $\mathrm{V}_{\mathrm{c}}$. The sources have been obtained with same amplitude and frequency but displaced $120^{\circ}$ out of the phase with each others. For carriers signals,

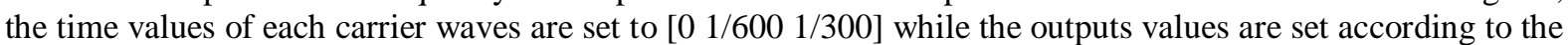
disposition of carrier waves. After comparing, the output signals of comparator are transmitted to the IGBTs. 


\section{Matlab/Simulink Modeling and simulation results:}

Here the simulation is carried out by three cases

1. Non-linear load Without DSTATCOM

2. Non-linear load with seven level PSCPWM cascaded multilevel DSTATCOM and

3. Non-linear load with seven level LSCPWM Cascaded multilevel DSTATCOM.

Case 1: Nonlinear load without DSTATCOM:

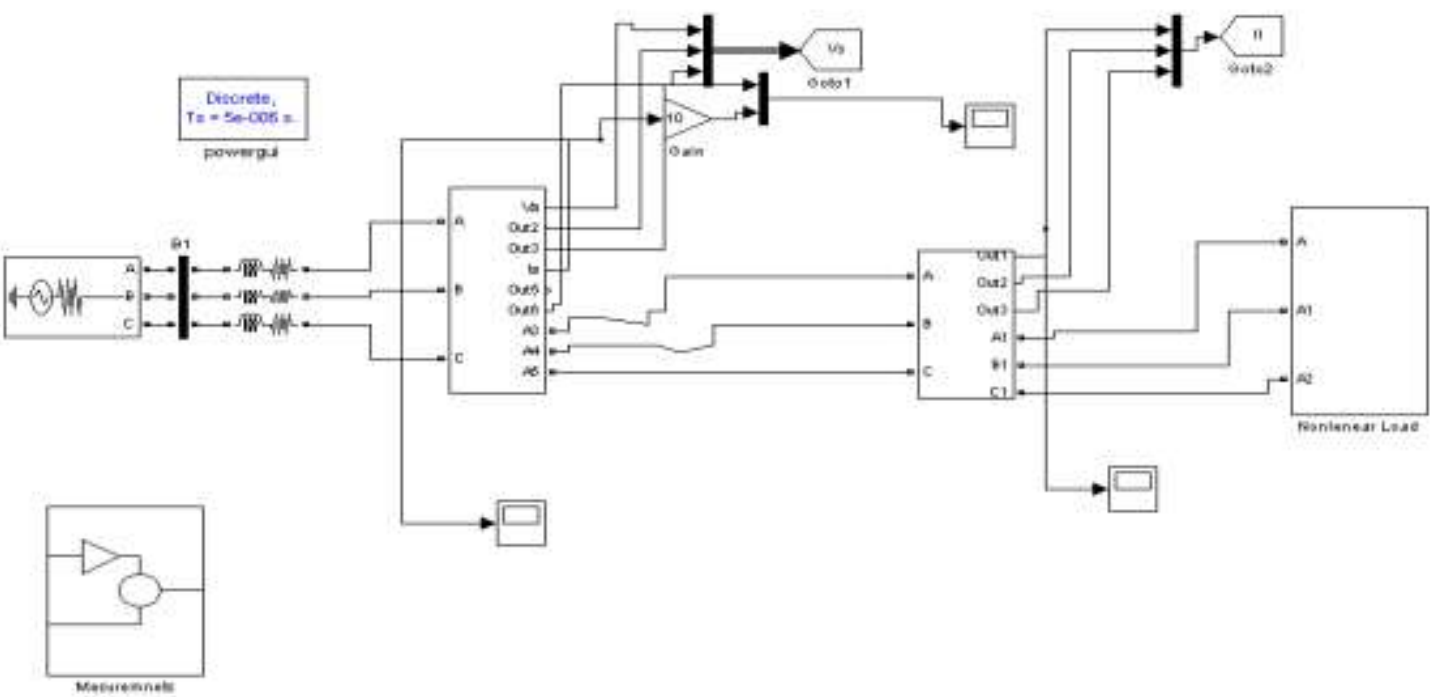

Figure 6 : Matlab/Simulink model of nonlinear load without DSTATCOM

Figure-7 shows the three phase source voltages, three phase source currents and load currents respectively without DSTATCOM. It is clear that without DSTATCOM load current and source currents are same.

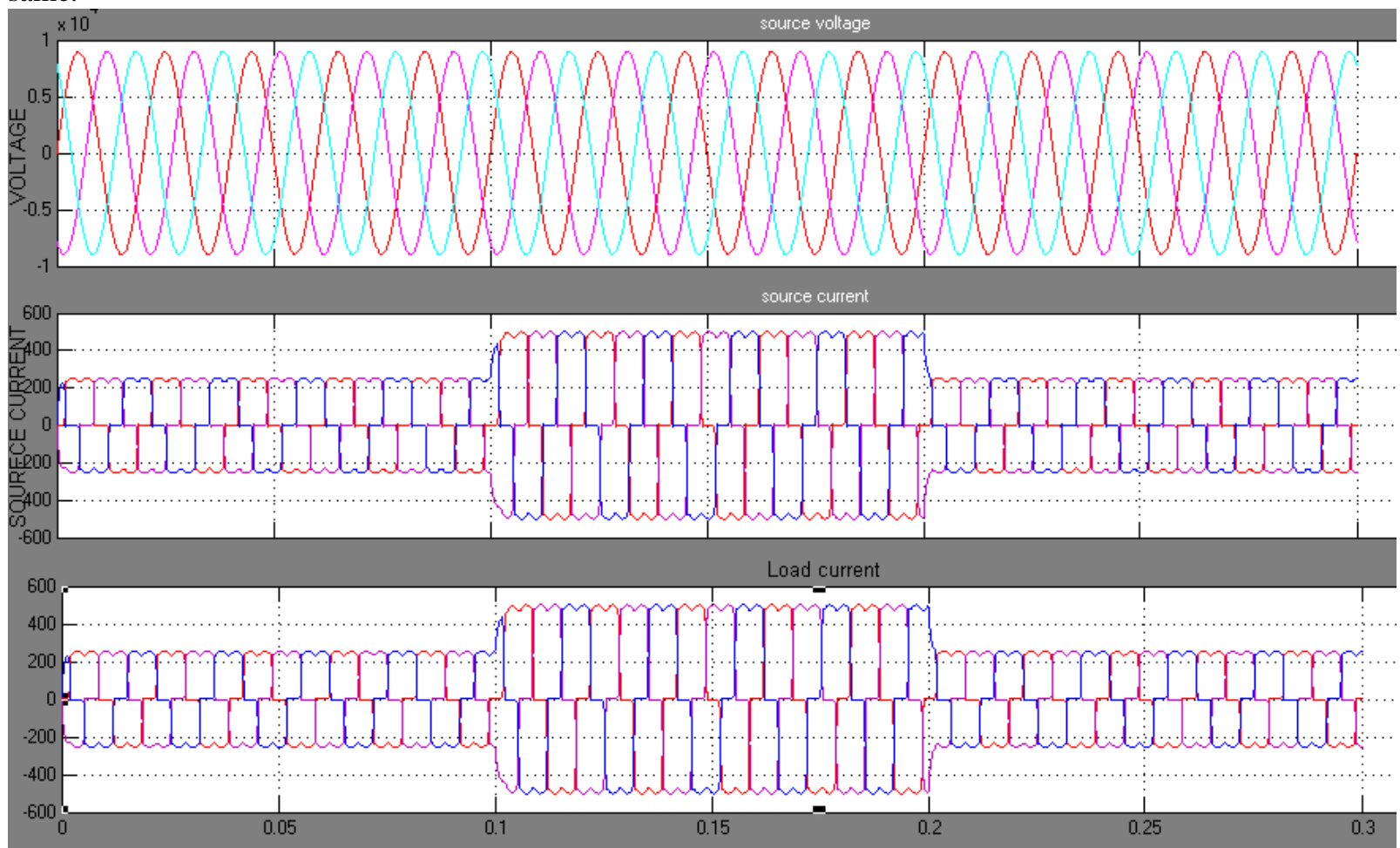

Figure 7: Source voltage, Source current, Load current

Case 2: Non-linear load with seven level PSCPWM cascaded multilevel DSTATCOM 


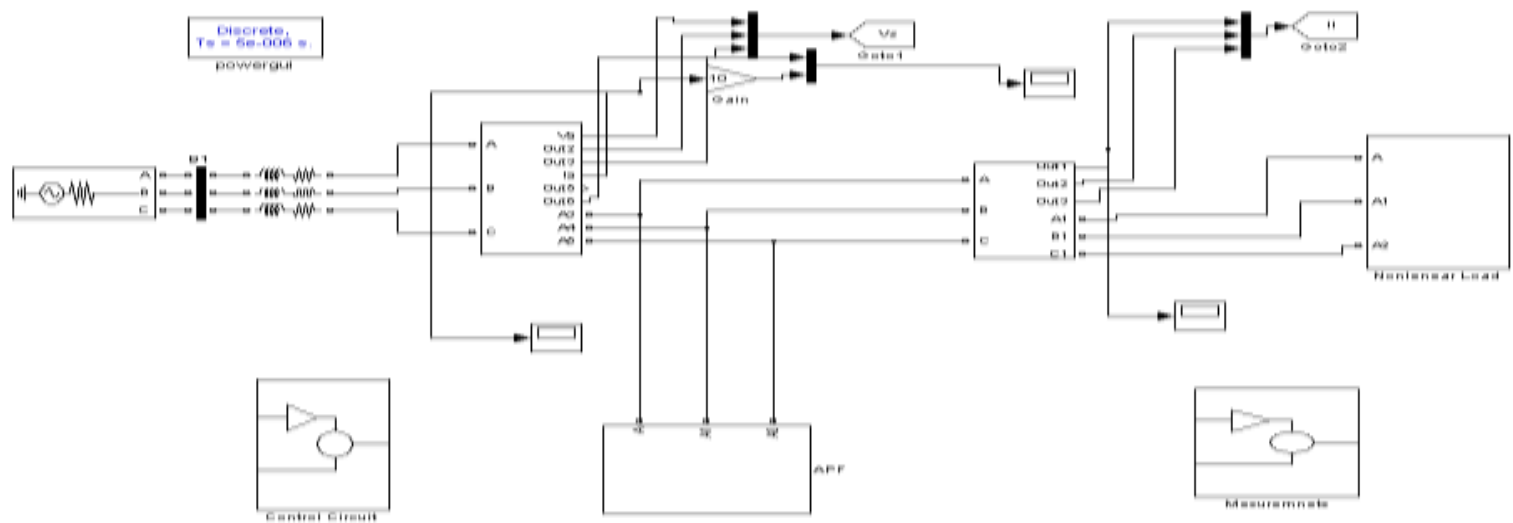

Figure 8: Matlab/Simulink Model of Nonlinear load with Five level Cascaded multilevel DSTATCOM

The performance of the proposed instantaneous real-power compensator cascaded seven level multilevel inverter based DSTATCOM is evaluated through Matlab/Simulink tools. The non-linear diode rectifier R-L load is connected with ac mains and cascaded active filter is connected in parallel at the PCC for injecting the antiharmonics and eliminating the harmonics and improving the Reactive power.

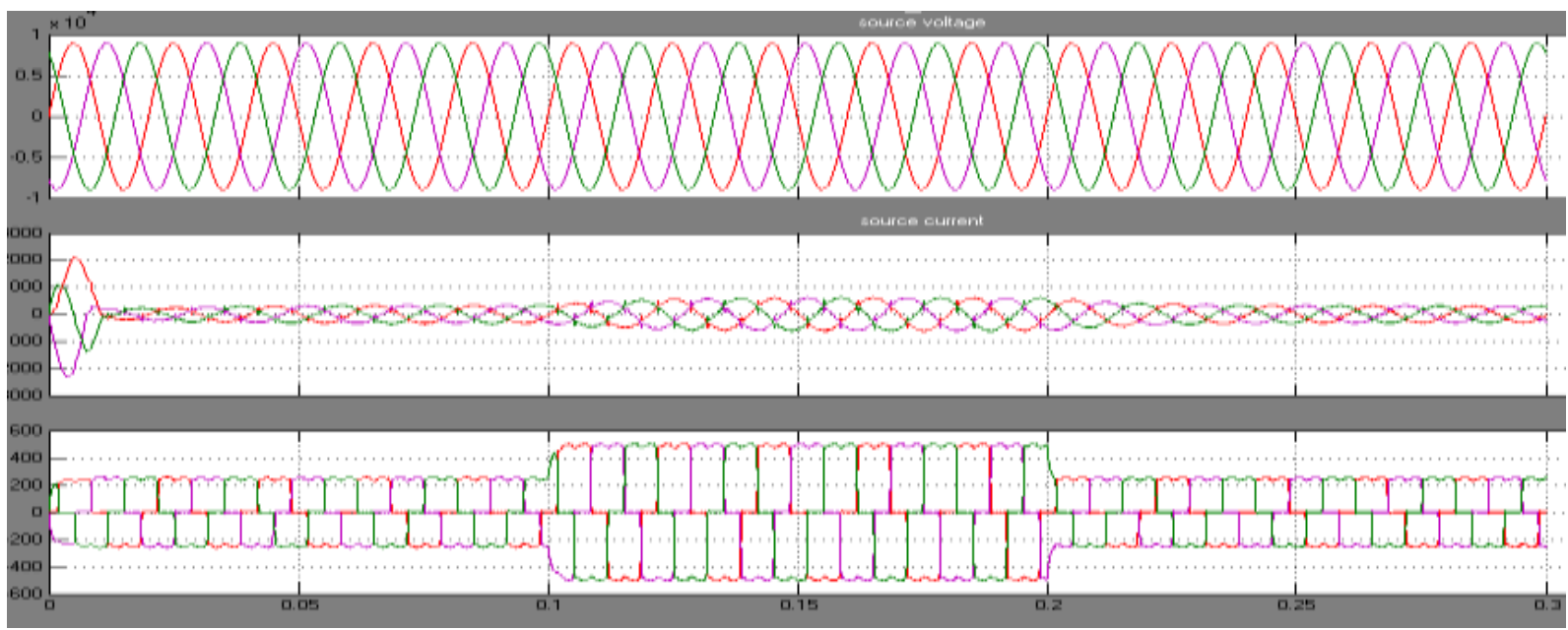

Figure 9: Source voltage, Source current, Load current

Figure-9 shows the three phase source voltages, three phase source currents and load currents respectively with Cascaded Multilevel five level Active power filter. It is clear that with DSTATCOM load current are same and source currents are compensated.

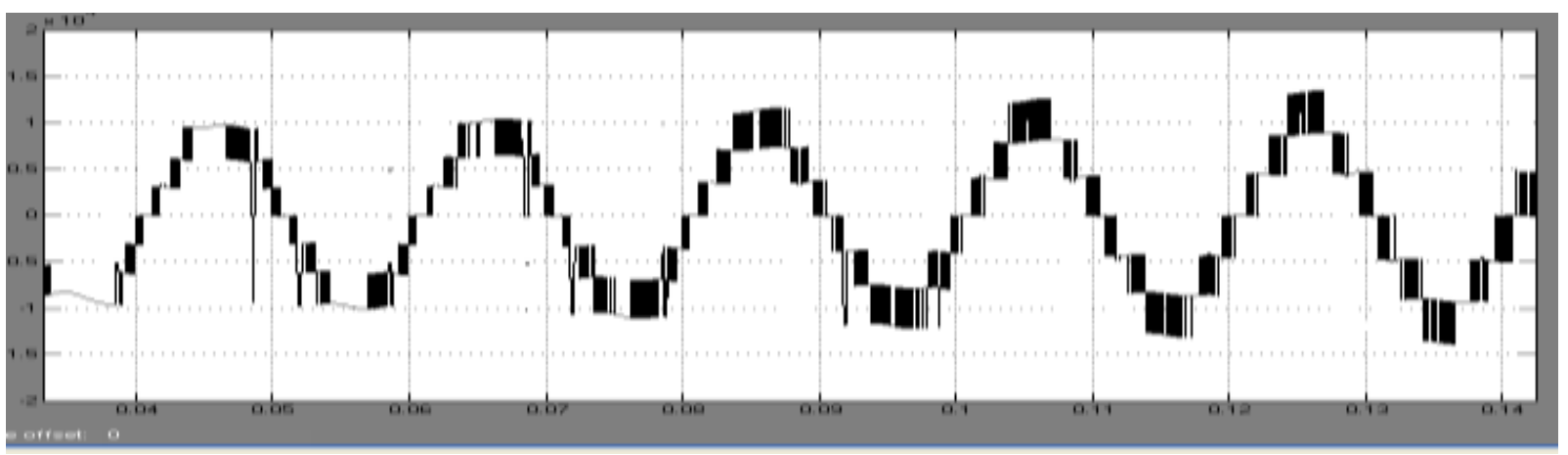

Figure. 10 Seven-level PSCPWM output

Figure 10 shows the seven level inverter output with Phase shifted Carrier pulse width modulation. From the figure we can clearly observe the seven voltage levels.

Figure. 11 shows the harmonic spectrum of Phase -A Source current without DSTATCOM. The THD of source current without DSTATCOM is $36.89 \%$. 

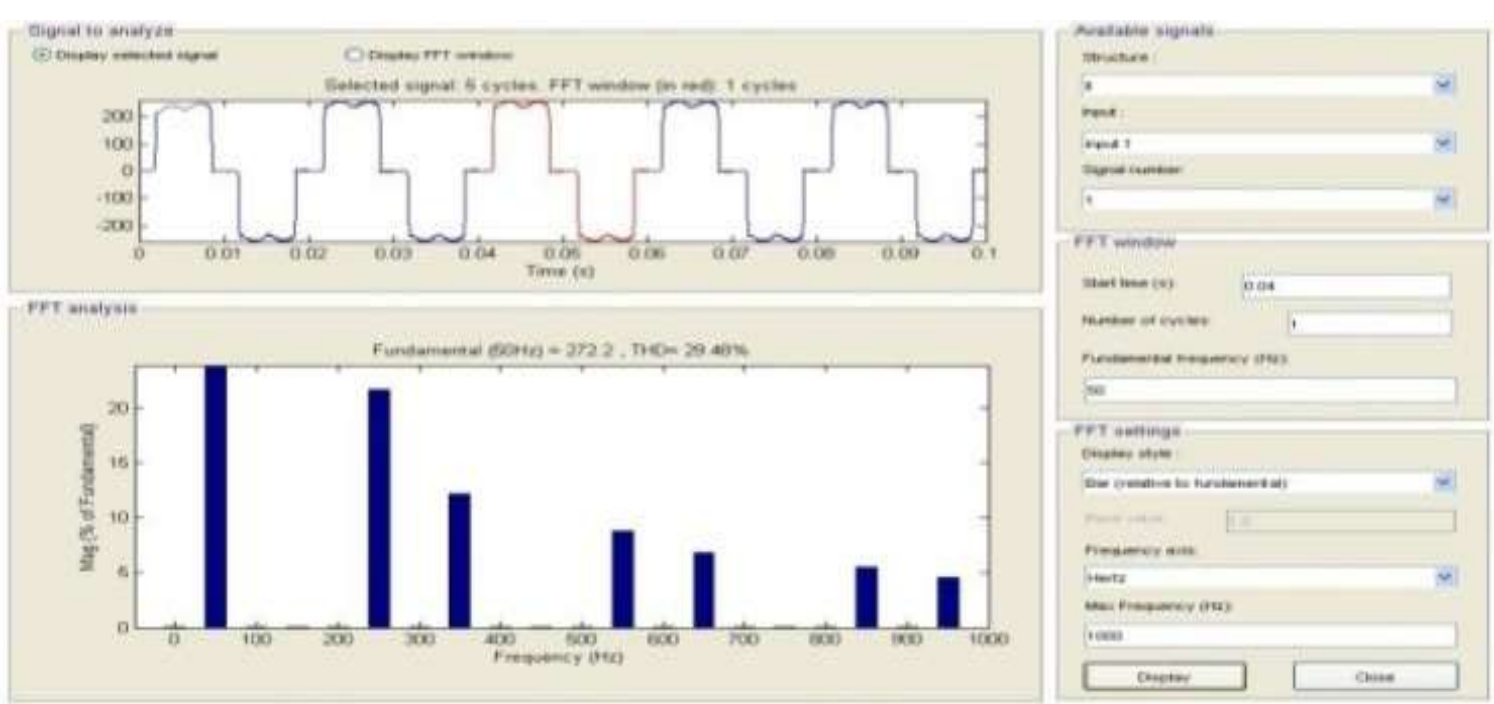

Figure. 11 Harmonic spectrum of Phase-A Source current without DSTATCOM

Figure12 shows the harmonic spectrum of Phase -A Source current with cascaded Multilevel Seven level PSCPWM with DSTATCOM. The THD of source current with Seven level DSTATCOM is $4.37 \%$.

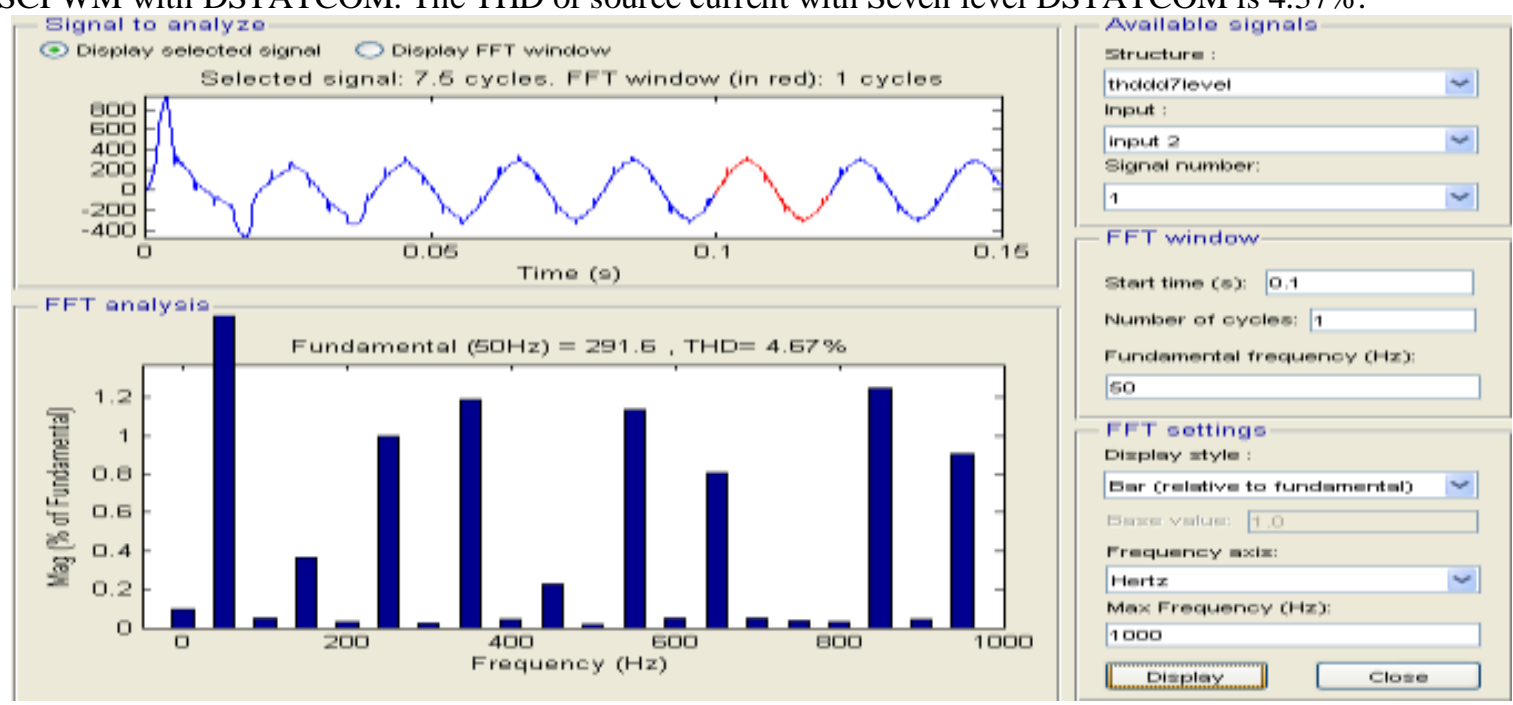

Figure. 12 Harmonic spectrum of Phase-A Source current with Seven level PSPWM DSTATCOM

Figure 13 shows the power factor waveforms of the designed system without DSTATCOM. The waveform clearly shows that there is no unity power factor.

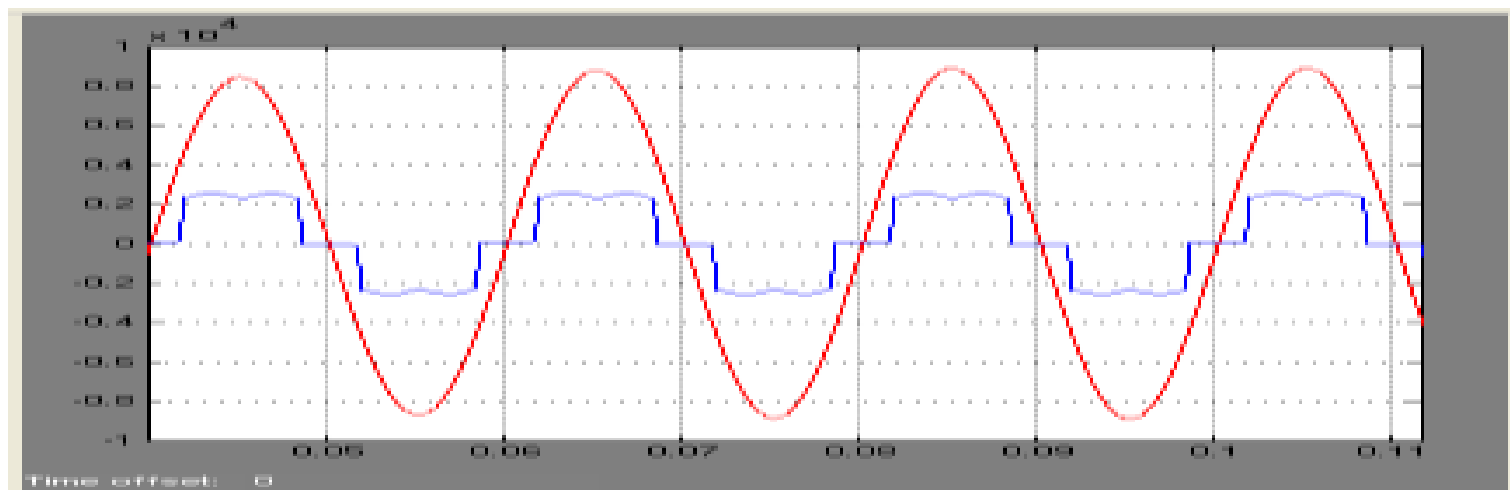

Figure 13: Power Factor without DSTATCOM

Figure 14 shows the power factor waveforms of the designed system with DSTATCOM. The waveform clearly shows that there is unity power factor where both the voltage and current are in phase. 


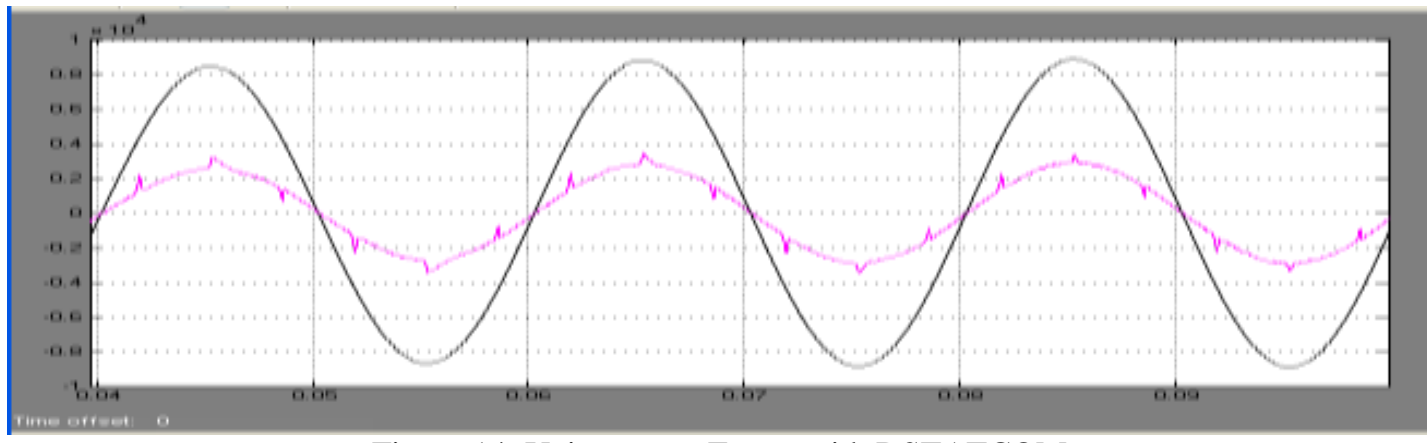

Figure 14: Unity power Factor with DSTATCOM

Case-3 Level shifted carrier PWM technique results

Figure. 15 shows the phase-A voltage of Seven level output of level shifted carrier PWM inverter.

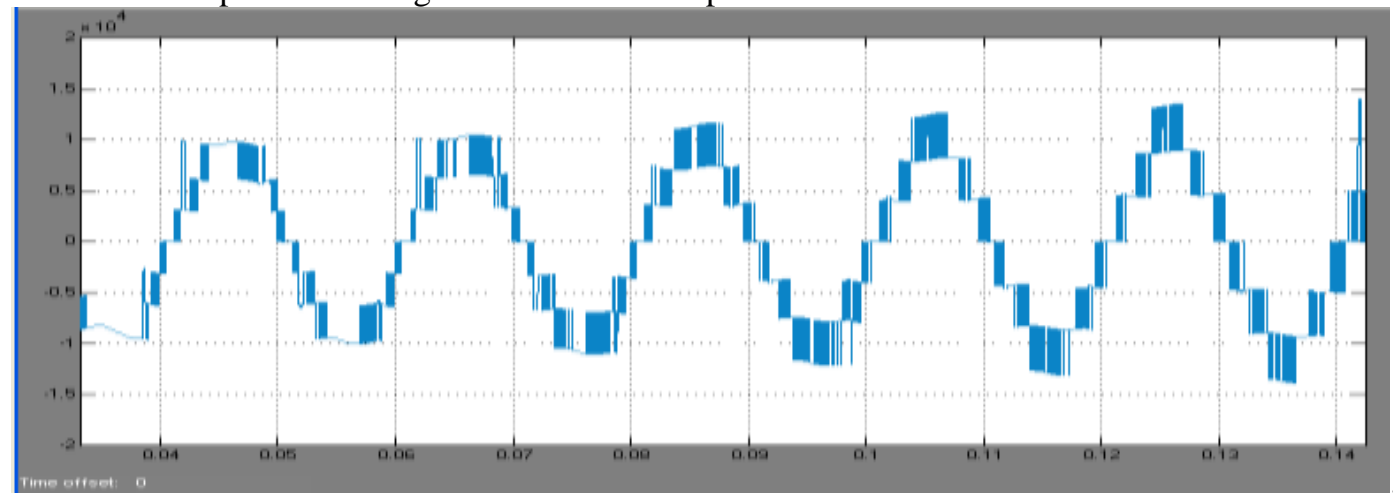

Figure. 15Seven level LSCPWM output

Figure-16 shows the three phase source voltages, three phase source currents and load currents respectively with Cascaded Multilevel Seven level LSCPWM - DSTATCOM. It is clear that with DSTATCOM load current are same and source currents are compensated.

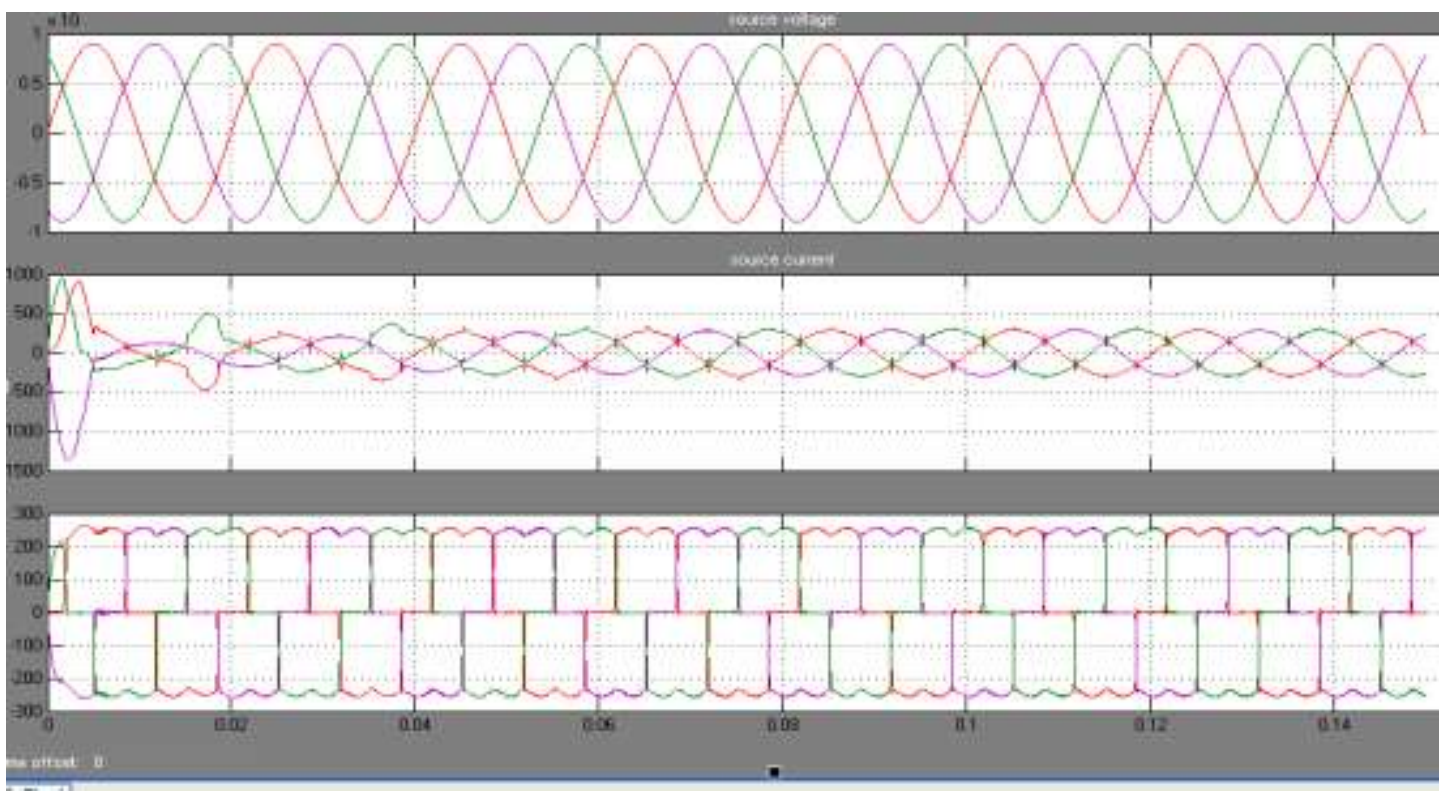

Figure 16: Source voltage, Source current, Load current

Figure 17. shows the harmonic spectrum of Phase -A Source current with cascaded Multilevel Seven level LSCPWM - DSTATCOM. The THD of source current with seven level DSTATCOM is $4.37 \%$. 

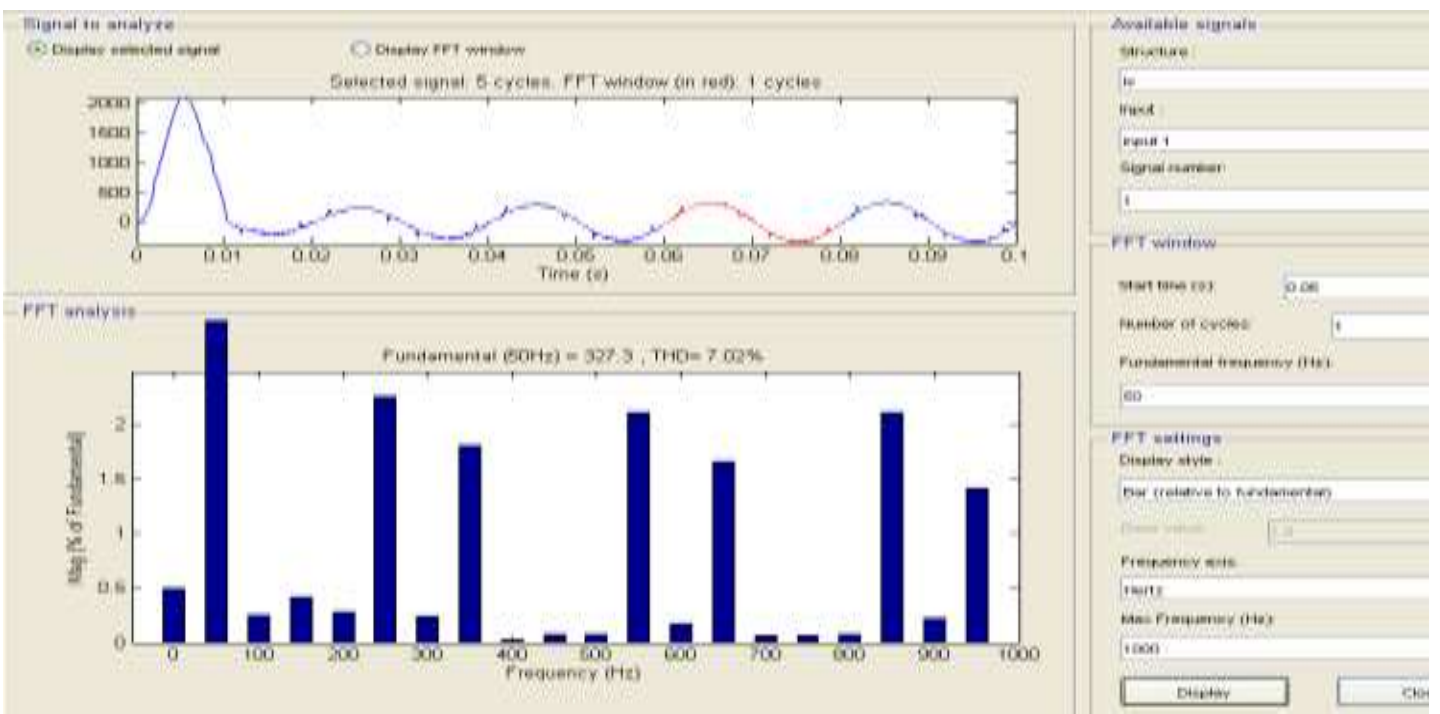

Figure. 17 Harmonic spectrum of Phase-A Source current with DSTATCOM

Table-II Comparison between the PSCPWM and LSCPWM schemes

\begin{tabular}{|l|l|l|}
\hline \multicolumn{1}{|c|}{ Comparison } & \multicolumn{1}{c|}{ PSPWM } & \multicolumn{1}{c|}{ LSPWM (IPD) } \\
\hline Device switching frequency & Same for all devices & Different \\
\hline Device conduction period & Same for all devices & Different \\
\hline Rotating of switching patterns & Not required & Required \\
\hline THD of Source Current & $4.37 \%$ & $2.82 \%$ \\
\hline
\end{tabular}

\section{Conclusion}

A seven level cascaded multilevel voltage source inverter based DSTATCOM using instantaneous realpower controller is found to be an effective solution for power line conditioning. DSTATCOM with the proposed controller reduces harmonics and provides reactive power compensation due to non-linear load currents; as a result source current(s) become sinusoidal and unity power factor is also achieved under both transient and steady state conditions. The proposed instantaneous real-power controller uses reduced computation for reference current calculations compared to conventional approach. The cascaded inverter switching signals are generated using triangular-sampling current controller; it provides a dynamic performance under transient and steady state conditions. As evident from the simulation studies, dc bus capacitor voltage settles early and has minimal ripple because of the presence of PI-controller. The THD of the source current is investigated for both PSCPWM and LSCPWM for a seven level inverter based DSTATCOM. THD simulation results under non-linear loads are investigated and found that the LSCPWM results are better than PSCPWM.

Table III: System Specifications

\begin{tabular}{|c|c|c|}
\hline S.No & System Parameters & Rating \\
\hline 1 & voltage & $11 \mathrm{kv}, 50 \mathrm{~Hz}$ \\
\hline 2 & Inductance & $0.9 \mathrm{e}-3 \mathrm{~h}$ \\
\hline 3 & Resistance & $0.1 \mathrm{ohm}$ \\
\hline 4 & Load & $\mathrm{R}=60, \mathrm{~L}=30 \mathrm{e}-3$ \\
\hline 5 & Inverter Parameters & DC Link voltage $=14 \mathrm{kv}$ \\
\hline
\end{tabular}

\section{References}

[1] Bhim Singh, Kamal Al-Haddad \& Ambrish Chandra, "A New Control Approach to 3-phase Active Filter for Harmonics and Reactive Power Compensation"-IEEE Trans. on Power Systems, Vol. 46, NO. 5, pp.133 - 138, Oct-1999

[2] W. K. Chang, W. M. Grady, Austin, M. J. Samotyj "Meeting IEEE- 519 Harmonic Voltage and Voltage Distortion Constraints with an Active Power Line Conditioner"- IEEE Trans on Power Delivery, Vol.9, No.3, pp.1531-1537, 1994

[3] Hirofumi Akagi, "Trends in Active Power Line Conditioners"- IEEE Trans on Power Electronics, Vol.9, No.3, May-1994

[4] W.M.Grady, M.J.Samotyj, A.H.Noyola "Survey of Active Power Line Conditioning Methodologies" IEEE Trans on Power Delivery, Vol.5, No.3, pp.1536-1542, July-1990

[5] L. Gyugyi, E. C. Strycula, “Active AC Power Filters”- in Proc. IEEE/IAS Annu. Meeting, Vol.19-c, pp 529-535, 1976

[6] Hirofumi Akagi, Yoshihira Kanazawa, Akira Nabae "Instantaneous Reactive Power Compensators Comprising Switching Devices without Energy Storage Components"- IEEE Trans on Industry Appl, Vol.I1-20, No.3,pp.625-630, 1984

[7] E. H. Watanabe, R. M. Stephan, M. Aredes, "New Concepts of Instantaneous Active and Reactive Powers in Electrical Systems with Generic Loads"- IEEE Trans. Power Delivery, Vol.8, No.2, pp.697-703, 1993 
[8] Fang Zheng Peng \& Jih-Sheng Lai, "Generalized Instantaneous Reactive Power Theory for Three-Phase Power Systems", IEEE Trans. on Inst. and Meast, Vol.45, No.1, pp.293-297, 1996

[9] Joao Afonso, Carlos Couto, Julio Martins “Active Filters with Control Based on the p-q Theory"- IEEE Industrial Elects Society Nletter-2000

[10] E. H. Watanabe, H. Akagi, M. Aredes "Instantaneous p-q Power Theory for Compensating Non sinusoidal Systems"- International School on Non sinlusoidal Currents and Compensation Lagow, Poland-2008

[11] Leszek S. Czarnecki "Instantaneous Reactive Power p-q Theory and Power Properties of Three-Phase Systems"- IEEE Trans on Power, VOL. 21, NO. 1, pp 362-367, 2006

[12] Karuppanan P and Kamala Kanta Mahapatra "Shunt Active Power Line Conditioners for Compensating Harmonics and Reactive Power"-Proceedings of the International Conference on Environment and Electrical Engineering (EEEIC), pp.277 - 280, May 2010

[13] Hirofumi Akagi, Akira Nabae and Satoshi Atoh "Control Strategy of Active Power Filters Using Multiple Voltage-Source PWM Converters” IEEE Trans on Industry Applications, Vol.IA-22, No.3, pp.460-465, May/June 1986

[14] Fang Zheng Peng, John W. McKeever, and Donald J. Adams "A Power Line Conditioner Using Cascade Multilevel Inverters for Distribution Systems” IEEE Trans on Industry Applications Vol.34, No.6, pp. 1293-98, Nov/Dec-1998

[15] S.-J.Huang and J.-C.Wu "Design and operation of cascaded active power filters for the reduction of harmonic distortions in a power System” IEE Proc.-Gener. Transm. Distrib.. Vol. 146, No. 2,pp. 193-199, March 1999.

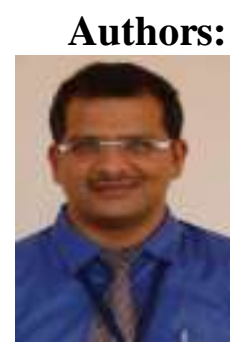

Mr. D. Mohan Reddy received the B.Tech. Degree in Electrical and Electronics Engineering from the JNT University, Hyderabad, India and he received the M.E Power Systems Engineering from Anna University Chennai and presently pursuing $\mathrm{PhD}$ from S.V.University,Tirupati,India. Presently he is working as an Associate Professor in the department of Electrical and Electronics Engineering in Sri Vasavi Institute of Engineering and Technology, Machilipatnam. His research areas of interests are power electronic converters, electrical drives and power quality.

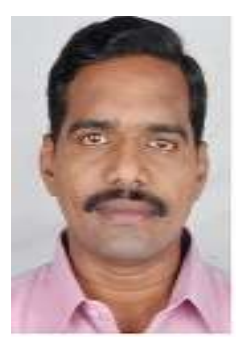

Dr T. Gowri Manohar received the B.Tech, M.Tech, and PhD Degrees in Electrical and Electronics Engineering from the S.V.University, Tirupati, India. Presently he is working as an Associate Professor in the department of Electrical and Electronics Engineering S.V.University, Tirupati, India. He is having 15 years of teaching experience and he was published 60 numbers of various international and national conferences \& journals. He is a senior Member of IEEE and also he is a member in Indian Society for Technical Education. His research areas of interests are Modern restructured power systems, electrical drives and power quality and harmonics -issues \& challenges. 